\title{
Oceanography
}

CITATION

Emerson, S.R., and S. Bushinsky. 2014. Oxygen concentrations and biological fluxes in the open ocean. Oceanography 27(1):168-171, http://dx.doi.org/10.5670/oceanog.2014.20.

$\mathrm{DOI}$

http://dx.doi.org/10.5670/oceanog.2014.20

COPYRIGHT

This article has been published in Oceanography, Volume 27, Number 1, a quarterly journal of The Oceanography Society. Copyright 2014 by The Oceanography Society. All rights reserved.

USAGE

Permission is granted to copy this article for use in teaching and research. Republication, systematic reproduction, or collective redistribution of any portion of this article by photocopy machine, reposting, or other means is permitted only with the approval of The Oceanography Society. Send all correspondence to: info@tos.org or The Oceanography Society, PO Box 1931, Rockville, MD 20849-1931, USA. 
SPECIAL ISSUE ON CHANGING OCEAN CHEMISTRY »

ANTHROPOCENE: THE FUTURE...SO FAR

\section{Oxygen Concentrations and Biological Fluxes in the Open Ocean}

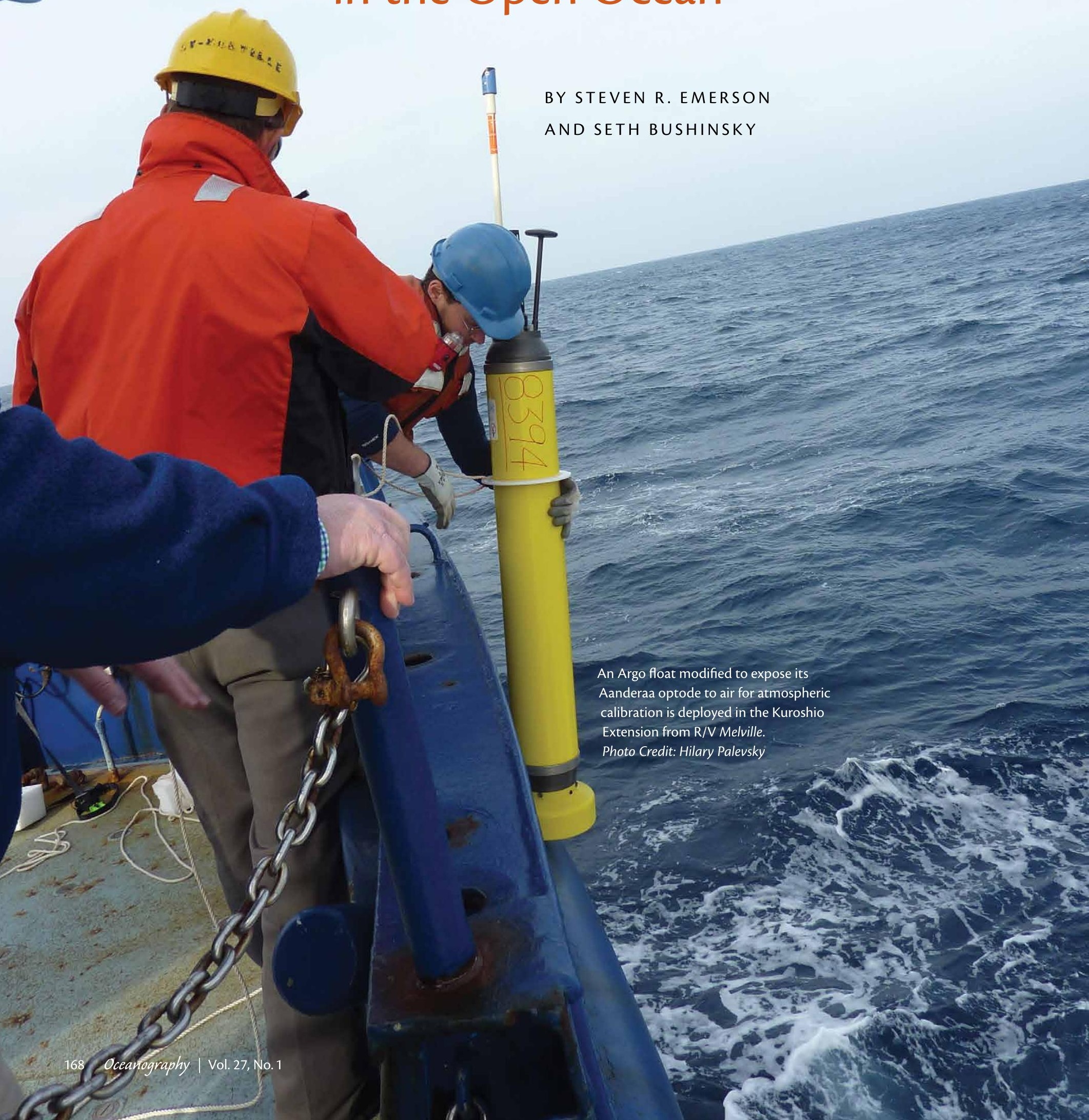


The oxygen concentration in the ocean is controlled by a delicate balance between the source from atmosphere-ocean interaction and net respiration of organic matter after the water leaves the surface and descends into the interior. Fossil fuel-induced warming is predicted in global circulation models to decrease both the subsurface oxygen concentration and the downward flux of organic carbon from the ocean's euphotic zone, with strong geographic variability in the responses of both. Oxygen concentrations have declined over the past 50 years in the few locations in the ocean thermocline where accurate long-term measurements exist. These observations are not, however, sufficiently widespread to determine global geographic variability nor long enough in duration to discern whether natural variations or anthropogenic effects cause these trends. Our challenge is to understand the mechanisms controlling oxygen concentration and to verify the carbon and oxygen cycle feedbacks predicted in global climate models. The cornerstone for achieving this goal is to obtain global coverage of accurate seasonal oxygen measurements in the ocean. It may be possible to do this by augmenting shipboard hydrographic studies with remote measurements of oxygen concentration using profiling floats, gliders, and moorings.

Interpreting seasonal cycles of oxygen concentration above the depth of the ocean's winter mixed layer has been one of the primary mass balance methods for determining annual net community production (ANCP), the annually integrated oxygen production in the upper ocean caused by the difference between photosynthetic production and respiratory consumption. Net oxygen production rates determined at a handful of open-ocean time-series sites are $4 \pm 2$ moles $\mathrm{O}_{2} \mathrm{~m}^{-2} \mathrm{yr}^{-1}$, which is equivalent to about $2.5 \pm 1.2$ moles of organic carbon exiting each square meter of the ocean's euphotic zone each year (see the compilation in Emerson, in press). These observations demonstrate not only that the open ocean is distinctly autotrophic (photosynthesis exceeds respiration) but region of the permanent thermocline. At steady state, the depth-integrated respiration rate should be related stoichiometrically to the organic carbon flux from above, and the respiration depth dependence is an important factor in determining the concentration of oxygen in the thermocline. Net respiration rates below the winter mixed layer

\section{S IT MAY BE POSSIBLE TO ACHIEVE ACCURATE OXYGEN CONCENTRATIONS ON PROFILING FLOATS BY CALIBRATING THE AANDERAA OPTODE OXYGEN SENSORS AGAINST ATMOSPHERIC $p \mathrm{O}_{2}$ WHEN THEY SURFACE AFTER EACH PROFILE TO TRANSMIT DATA HOME VIA SATELLITE.}

also that there is little latitudinal variability in net biological organic carbon and oxygen production in the open ocean. Global estimates of ANCP derived from satellite-based remote sensing and global circulation models (GCMs) give a different picture, with low ANCP in subtropical regions and much higher values at the equator and in high latitudes, similar to distributions of near-surface nutrients. The cause of the difference between these estimates of ANCP geographic variability could be that there are too few experimental measurements to detect true global heterogeneity or that satellite observations and GCM predictions are missing some critical component(s). Resolving this issue will require much greater global coverage of seasonal experimental measurements.

Net respiration by bacteria and other heterotrophs results in the decrease in oxygen concentration below the depth of the wintertime mixed layer in the upper are less than $0.1 \mu \mathrm{mol} \mathrm{kg} \mathrm{kg}^{-1} \mathrm{~d}^{-1}$ too low to measure directly, so oceanographers determine these rates by correlating apparent oxygen utilization $\left(\mathrm{AOU}=\left[\mathrm{O}_{2}\right]_{\text {sat }}-\left[\mathrm{O}_{2}\right]_{\text {meas }}\right)$ and the ventilation age of the water. In locations where ventilation is slow and/or organic matter supply from above is high, oxygen is almost entirely consumed. It is essential to understand the processes controlling the extent of these low-oxygen waters because they are uninhabitable by marine animals and mark the boundary of water column denitrification (see Brewer and Hofmann, 2014, and Fulweiler and Heiss, 2014, in this issue). There is no reason to expect that subsurface oxygen concentrations should be static. Indeed, at two locations where there have been accurate measurements for decades (in the North Pacific, Whitney et al., 2007; and in the North Atlantic, Stendardo and Gruber, 2012), there is a gradual decline in oxygen 
concentration in the thermocline over the past 50 years at rates between 0.3 and $0.7 \mu \mathrm{mol} \mathrm{kg}{ }^{-1}$ per year. These decreases are much greater than can be explained by the change in solubility in response to ocean warming. Future measurements and models that can accurately reproduce the oxygen minimum zones will help establish whether these changes are part of natural long-term cycles or the result of decreased ventilation and/or increased respiration due to global warming.

The ability to reproduce measured deep-ocean oxygen concentrations has only recently been achieved in global circulation models. Model projections suggest a small decrease in both the biological pump and the volume integrated subsurface ocean $\mathrm{O}_{2}$ concentration by the year 2100 as a result of global warming (less than $10 \%$ and 5\%, respectively; Bopp et al., 2013; Doney et al., 2014, in this issue). While the predicted globally integrated feedback to climate change is modest, regional future ocean changes are much more dramatic. Increased stratification reduces ANCP in the equatorial region, with a corresponding increase in thermocline oxygen concentration, while the biological pump is predicted to increase in high latitudes with a corresponding decline in oxygen concentration in the thermocline. These oxygen concentration changes are in the same direction as measured multidecadal observations in the North Pacific and North Atlantic; however, the predicted changes would be more convincing if we knew that the GCMs were able to reproduce the presently observed global ANCP distribution.

The paleoclimate record is useful for assessing the sensitivity of environmental conditions to change. For example, knowing how global temperature and atmospheric $\mathrm{CO}_{2}$ changed during the most recent glacial to interglacial transition helps to test mechanisms that caused the change and inform projections of future response. Using the paleorecord to constrain models that predict future carbon export and oxygen change is a bigger challenge because proxies for past changes in these values in both sediment and ice cores are relatively blunt instruments. The presence or absence of sedimentary fossils of benthic organisms and laminations is a clear indicator of the difference between oxic and anoxic bottom water; however, proxies for the content of bottom water oxygen are still mostly qualitative (see Jaccard et al., 2014, in this issue).

Without quantitative paleoproxies for either organic carbon export or bottom water oxygen concentration, the most obvious way to test the accuracy of ocean model-predicted changes in response to global warming is to develop a contemporaneous archive of accurate global and seasonal oxygen concentrations. Values in the surface ocean can be used to determine net biological oxygen production and the stoichiometrically associated downward carbon export, and values in the thermocline can be used to monitor the geographic distribution of changes in the oxygen minimum through time. Repeat hydrographic measurements on decadal time scales are essential to validate accuracy but cannot resolve seasonality, which is necessary to determine ANCP. Seasonal measurements of oxygen at ocean time-series locations are important for assessing

Steven R. Emerson (emerson@u.washington.edu) is Professor and Seth Bushinsky is PhD Candidate, School of Oceanography, University of Washington, Seattle, WA, USA.

the consistency of ANCP determinations from satellite remote sensing, oxygen mass balances, and sediment trap fluxes (Emerson, in press), but the infrastructure for time-series sites is too expensive to expand their number into global coverage.

The most promising means for achieving global, seasonal coverage of oxygen concentrations is through remote measurements on profiling floats. There are presently about 3,500 Argo floats distributed globally, each making repeat profiles of temperature and salinity on a roughly weekly basis as they drift with the currents. Several hundreds of these floats are equipped with oxygen sensors, but they are presently not accurate to better than plus or minus 3\% (Takeshita et al., 2013). This inaccuracy is at about the same level as the expected supersaturation in the ocean mixed layer due to net community production, and represents over a decade of change in concentration in the upper thermocline using presently observed trends. Clearly, more accurate measurements must be made to utilize this resource optimally.

It may be possible to achieve accurate oxygen concentrations on profiling floats by calibrating the Aanderaa optode oxygen sensors against atmospheric $p \mathrm{O}_{2}$ when they surface after each profile to transmit data home via satellite (Figure 1). It is not sufficient to have detailed laboratory calibrations because some of these sensors drift by several percent per year at room temperature. Recently, we found that oxygen concentrations determined using optodes on Argo floats calibrated five months earlier in our laboratory were several percent less than simultaneous measurements made by Winkler titrations on deployment. After correcting the float optode 
data to atmospheric measurements

(Figure 1, red line), they agree extremely well with independent Winkler-

calibrated mooring data (Figure 1, black line). This indicates that it is possible to calibrate these oxygen sensors in situ against the $\mathrm{pO}_{2}$ of the atmosphere over a period of at least one year. Fiedler et al. (2013) describe a similar experiment done on shorter time scales in the North Atlantic. While promising, there are still uncertainties in this approach that have to be further constrained. For example, to derive ANCP from surface oxygen data, it is necessary to determine what fraction of the degree of supersaturation is due to bubble processes that inject oxygen into the surface ocean. Also, to monitor oxygen changes in the ocean interior, it must be shown that accurate low concentration oxygen measurements can be determined from surface ocean "one-point" calibrations (air $\mathrm{pO}_{2}$ ) together with laboratory-determined oxygen sensitivities.

\section{ACKNOWLEDGEMENTS}

We would like to thank Steve Riser and Dana Swift at the University of Washington for their collaboration on

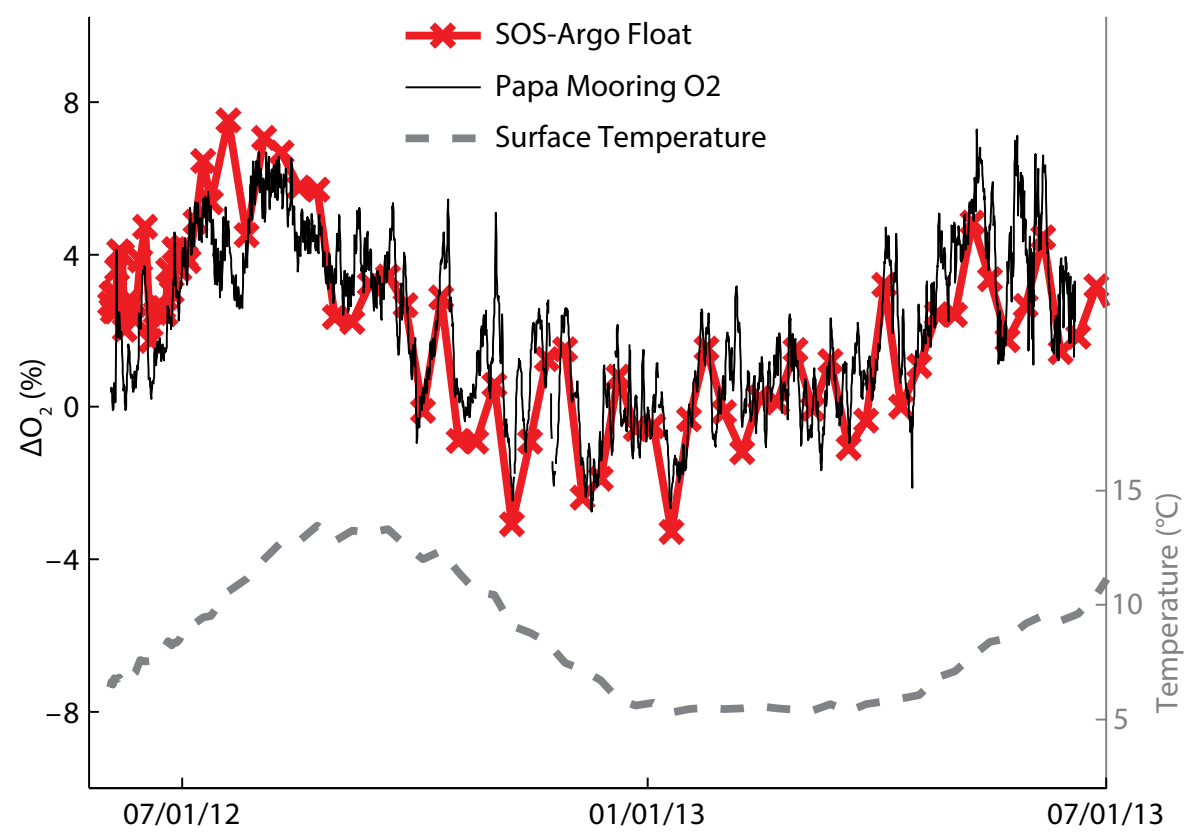

Figure 1. The degree of oxygen supersaturation in surface waters of the ocean near Ocean Station Papa (OSP; $50^{\circ} \mathrm{N}, 145^{\circ} \mathrm{W}$ ) determined by in situ methods over a period of one year. The black line goes through data points determined using an Aanderaa optode that makes measurements every three hours on a surface mooring at about $2 \mathrm{~m}$ depth. The optode was calibrated by Winkler titrations when ships visited OSP in June and August of 2012 and June of 2013. Sensor drift over one year was about $-3 \%$. The red line is the oxygen supersaturation determined from an Aanderaa optode sensor on a profiling Argo float especially configured to measure $\mathrm{pO}_{2}$ of the atmosphere when the float surfaces every 5 to 10 days. Optode accuracy is calibrated against the $p \mathrm{O}_{2}$ of the atmosphere: $p \mathrm{O}_{2}$ $=\left(\mathrm{P}_{\mathrm{atm}}-p_{\mathrm{H} 2 \mathrm{O}}\right) \times 0.20964$. Total atmospheric pressure, $\mathrm{P}_{\mathrm{atm}}$, is determined from National Centers for Environmental Prediction (NCEP) reanalysis. The authors assume that the partial pressure of water in the atmosphere, $p_{\mathrm{H} 2 \mathrm{O}}$, within one meter of the water surface is equal to that in saturated air, and that 0.20964 is the mixing ratio of oxygen in the dry atmosphere. The optode on the profiling float did not drift detectably during the year, probably because it spends $98 \%$ of its life at $1,000 \mathrm{~m}$ and $2^{\circ} \mathrm{C}$ (recent work of authors Bushinsky and Emerson).

the oxygen float project. Marie Robert from the Institute of Ocean Sciences, Sidney, BC, and the crew of CCGS Tully helped us deploy the float at Ocean Station Papa. This research was supported by NSF grant OCE-1129112. [d

\section{REFERENCES}

Bopp, L., L. Resplandy, J.C. Orr, S.C. Doney, J.P. Dunne, M. Gehlen, P. Halloran, C. Heinze, T. Ilyina, R. Séférian, and others. 2013. Multiple stressors of ocean exosystems in the $21^{\text {st }}$ century: Projections with CMIP5 models. Biogeosciences 10:6,225-6,245, http://dx.doi.org/ 10.5194/bg-10-6225-2013.

Brewer, P.G., and A.F. Hofmann. 2014. A plea for temperature in descriptions of the oceanic oxygen status. Oceanography 27(1):160-167, http:// dx.doi.org/10.5670/oceanog.2014.19.

Doney, S.C., L. Bopp, and M.C. Long. 2014. Historical and future trends in ocean climate and biogeochemistry. Oceanography 27(1):108-119, http://dx.doi.org/ 10.5670/oceanog.2014.14.

Emerson, S. In press. Annual net community production and the biological carbon flux in the ocean. Global Biogeochemical Cycles, http:// dx.doi.org/10.1002/2013GB004680.

Fiedler, B., P. Fietzek, N. Vieira, P. Silva, H.C. Bittig, and A. Körtzinger. 2013. In situ $\mathrm{CO}_{2}$ and $\mathrm{O}_{2}$ measurements on a profiling float. Journal of Atmospheric and Oceanic Technology 30:112-126, http://dx.doi.org/ 10.1175/JTECH-D-12-00043.1.

Fulweiler, R.W., and E.M. Heiss. 2014. (Nearly) a decade of directly measured sediment $\mathrm{N}_{2}$ fluxes: What can Narragansett Bay tell us about the global ocean nitrogen budget? Oceanography 27(1):184-195, http://dx.doi.org/ 10.5670/oceanog.2014.22.

Jaccard, S.L., E.D. Galbraith, T.L. Frölicher, and N. Gruber. 2014. Ocean (de)oxygenation across the last deglaciation: Insights for the future. Oceanography 27(1):26-35, http://dx.doi.org/ 10.5670/oceanog.2014.05.

Stendardo, I., and N. Gruber. 2012. Oxygen trends over five decades in the North Atlantic. Journal of Geophysical Research 117, C11004, http:// dx.doi.org/10.1029/2012JC007909.

Takeshita, Y., T.R. Martz, K.S. Johnson, J. Plant, D. Gilbert, S. Riser, C. Neil, and B. Tilbrook. 2013. A climatology-based quality control procedure for profiling float oxygen data. Journal of Geophysical Research 118:5,640-5,650, http://dx.doi.org/10.1002/jgrc.20399.

Whitney, F.A., H.J. Freeland, and M. Robert. 2007. Persistently declining oxygen levels in the interior waters of the eastern subarctic Pacific. Progress in Oceanography 75:179-199, http://dx.doi.org/10.1016/j.pocean.2007.08.007. 